\title{
ANALISIS INDEKS KEBERLANJUTAN USAHA PEMBESARAN LOBSTER DI PULAU LOMBOK PROVINSI NUSA TENGGARA
} BARAT

\author{
Ervin Nora Susanti ${ }^{1}$, Rina Oktaviani ${ }^{2}$, Sri Hartoyo ${ }^{2}$, dan Dominicus Savio Priyarsono ${ }^{2}$ \\ ${ }^{1}$ Program Studi Manajemen, Fakultas Ekonomi Universitas Riau Kepulauan, \\ Jl. Batu Aji Baru No 99 Batam, Kepulauan Riau \\ ${ }^{2}$ Departemen Ilmu Ekonomi, Fakultas Ekonomi dan Manajemen \\ Institut Pertanian Bogor (IPB), Bogor, Indonesia 16680 \\ Email: ervin.nora@gmail.com
}

\begin{abstract}
ABSTRAK
Keberhasilan implementasi pertanian berkelanjutan tidak hanya terkait pada keamanan ketersediaan pangan secara nasional, tetapi juga terkait dengan peran penting sektor pertanian dalam perekonomian nasional. Unit-unit kegiatan usahatani yang berorientasi pada keberlanjutan usaha akan menjadi penggerak bagi perekonomian. Usaha pembesaran lobster merupakan salah satu unit kegiatan sektor perikanan yang memiliki kontribusi bagi perekonomian. Keberhasilan usaha pembesaran lobster yang berkelanjutan dipengaruhi oleh keterlibatan beberapa pihak termasuk petani. Petani merupakan subjek yang terlibat langsung dalam pelaksanaan konsep pembangunan pertanian berkelanjutan dilapangan. Persepsi petani terhadap keberlanjutan usaha bisa menjadi tolok ukur keberhasilan pertanian berkelanjutan di tingkat usahatani. Penelitian ini bertujuan untuk menganalisis tingkat keberlanjutan menggunakan indeks komposit dari data skala likert persepsi petani terhadap keberlanjutan usaha pembesaran lobster. Data skala likert yang merupakan skala ordinal ditransformasikan ke dalam skala interval menggunakan pendekatan Method of Succesive Interval (MSI). Pengumpulan data dilakukan melalui survey kepada 106 petani lobster di Pulau Lombok Provinsi Nusa Tenggara Barat menggunakan kuesioner terstruktur. Hasil penelitian menunjukkan bahwa nilai indeks persepsi keberlanjutan untuk dimensi ekonomi, sosial dan lingkungan masing-masing masuk pada katagori keberlanjutan "sedang" dengan nilai rata-rata adalah $0.58 ; 0.56$ dan 0.54 . Indeks gabungan yang merupakan interaksi antara ketiga dimensi memiliki rata-rata 0.56 juga masuk pada katagori "sedang".
\end{abstract}

Kata kunci : pertanian berkelanjutan, indeks keberlanjutan, persepsi petani, budidaya lobster

\begin{abstract}
The successful of sustainable farming implementation is not only related to the security of food supply, but also to the contribution to national economy. Sustainability oriented farming will become a motor for the economy. One of contributing unit is lobster farming. The success of sustainable lobster farming is affected by the involvement of multiple parties, including the farmers. Farmers are the subject who directly involved in implementing the concept of sustainable agricultural development. The farmers's perception of sustainability is a benchmark of successful sustainable agriculture at the farm level. This study aimed to analyze sustainability level by using the composite index of the likert scale data on the perception of farmers towards farming sustainability. Likert ordinal scale data is transformed into interval scale using Method of Successive Interval (MSI). Data collected through a survey to 106 farmers in Lombok Island, West Nusa Tenggara province using a structured questionnaire. The results suggest that the value of the index of sustainability perception for the economic, social and environment each fall into"moderate" category with the average value is $0.58,0.56$ and 0.54 respectively. The Composite index, interaction between aspects, have an average of 0.56 is also fall into the "moderate" category.
\end{abstract}

Keywords: sustainable agriculture, sustainability index, farmers perception, lobster farming 


\section{PENDAHULUAN}

Perikanan berkelanjutan adalah upaya memadukan tujuan sosial, ekonomi dan ekologi. Aktivitas perikanan yang berkelanjutan dapat dicapai melalui pengelolaan perikanan yang tepat dan efektif, yang umumnya ditandai dengan meningkatnya kualitas hidup dan kesejahteraan manusia serta terjaganya kelestarian sumber daya ikan dan kesehatan ekosistem (Kementerian PPN/Bappenas, 2014). Menurut Bhossaq et al (2012) implementasi pembangunan berkelanjutan adalah hasil interaksi dari berbagai dimensi keberlanjutan, tiga dimensi penting yang sering dijadikan acuan adalah ekonomi, sosial dan lingkungan.

Pelaku usaha di sektor perikanan, termasuk pembudidaya merupakan pihak yang secara langsung terlibat dalam impelementasi konsep keberlanjutan pembangunan. Pada level petani, ruang lingkup aspek keberlanjutan yang diukur mempunyai kriteria khusus, karena petani adalah subjek yang terlibat langsung dengan sumber daya yang ada dan tidak mudah dalam mengukurnya, dibandingkan dengan penetapan alat ukur pada tingkat makro (Waryanto, 2015).

Beberapa peneliti menggunakan indikator yang berbeda-beda dalam mengukur tingkat keberlanjutan di tingkat petani. Bosshaq et al. (2012) menggunakan kisaran skala likert sangat rendah, rendah, sedang, tinggi dan sangat tinggi dan mengakomodir pilihan "none", dengan rentang skor 0 sampai 5. Indikator dimensi sosial, ekonomi dan lingkungan yang digunakan seluruhnya berjumlah 31. Bagheri et al (2008) menggunakan skala likert 1-5 (1 "sangat tidak setuju", 2 "tidak setuju", 3 "ragu-ragu", "setuju" dan 5 "sangat setuju") untuk mengukur persepsi petani padi terhadap indikator keberlanjutan teknologi pertanian. Studi literatur Hayati et al. (2011) tentang indikator keberlanjutan pada tingkat usaha tani menghasilkan 10 indikator dimensi ekonomi, 18 indikator dimensi ekologi/lingkungan dan 9 indikator dimensi sosial. Indikator-indikator tersebut dapat dijadikan sebagai alat ukur pada analisis keberlanjutan suatu kegiatan usaha tani yang metode analisisnya dapat disesuaikan menurut kebutuhan.

Penelitian ini bertujuan untuk menganalisis tingkat keberlanjutan usaha pembesaran lobster menggunakan indeks komposit dari data skala likert persepsi petani.
Persepsi petani terhadap keberlanjutan usaha bisa menjadi tolok ukur keberhasilan pertanian berkelanjutan di tingkat usahatani, karena petani merupakan subjek yang terlibat langsung dalam pelaksanaan konsep pembangunan berkelanjutan.

\section{METODE PENELITIAN}

Data dalam penelitian ini adalah data primer hasil wawancara terhadap 106 orang pembudidaya lobster di Desa Jerowaru dan Desa Pare Mas Kecamatan Jerowaru Kabupaten Lombok Timur. Lokasi penelitian dipilih secara purposive adalah sentra usaha budidaya pembesaran lobster di Pulau Lombok. Pemilihan sampel dilakukan menggunakan teknik sampling snowball, karena jumlah populasi pembudidaya lobster sulit diketahui dengan pasti.

Indeks keberlanjutan diukur dengan cara membuat indeks komposit berdasarkan data skala likert yang merupakan pernyataan operasional dari kebiasaan petani (Ceyhan, 2010; Gunduz et al., 2011; Waryanto, 2015). Pernyataan keberlanjutan dirumuskan ke dalam 30 variabel (10 dimensi ekonomi, 10 dimensi sosial dan 10 dimensi lingkungan) dengan skor nilai 1-5 (1 "sangat tidak setuju", 2 "tidak setuju", 3 "ragu-ragu", "setuju" dan 5 "sangat setuju").

Pemilihan variabel dilakukan dengan mengacu pada hasil penelitian Hayati et al. (2011) dan Waryanto (2015). Skala likert merupakan skala ordinal, sehingga perlu dilakukan transformasi ke skala interval menggunakan pendekatan Method of Successive Interval/MSI (Waryanto dan Millafati 2006). Transformasi dilakukan untuk bisa menghitung nilai rataan $\left(X_{j}\right)$, nilai $\operatorname{Min} X_{j}$ dan nilai Max $X j$ serta nilai standar deviasi.

Rumus perhitungan indek komposit secara umum disajikan pada persamaan (1) dan persamaan (2):

$I_{j i}=\frac{\left[X_{j i}\right]-\left[\operatorname{MaxX}_{j}\right]}{\left[\operatorname{MinX}_{j}-\operatorname{MaxX}_{j}\right]}$

Atau

$I_{j i}=\frac{\left[\operatorname{Max}_{j}\right]-\left[X_{j i}\right]}{\left[\operatorname{Max} X_{j}-\operatorname{Min} X_{j}\right]}$

Dimana $I_{j i}$ adalah nilai indeks keberlanjutan variabel ke-j dan petani ke-i; $X_{j i}$ adalah nilai hasil pengukuran dari setiap variabel ke-j dan petani ke-i; $\operatorname{Min}_{j}$ adalah nilai terendah hasil pengukuran variable $\mathrm{j}$; 
$\operatorname{Max}_{j}$ adalah nilai tertinggi hasil pengukuran variabel $\mathrm{j}$; $\mathrm{j}$ adalah variabel $\mathrm{ke} 1,2, \ldots, \mathrm{k}$; dan $\mathrm{i}$ adalah responden ke $1,2, \ldots, \mathrm{n}$

Nilai indek komposit keberlanjutan berada pada kisaran 0 sampai 1 . Pengklasifikasian indeks keberlanjutan menurut kriteria Gunduz (2011) : 1) kelompok indeks keberlanjutan "rendah" (skor nilai 0 sampai 0.40), 2) skor kelompok indeks keberlanjutan "sedang" (skor nilai 0.41 sampai 0.67), dan 3) kelompok indeks keberlanjutan "tinggi" (skor nilai 0.68 atau lebih).

\section{HASIL DAN PEMBAHASAN}

Karakteristik Responden. Rata-rata tingkat pendidikan responden rendah, 29 orang responden tidak tamat SD dan 52 orang tamat SD, 18 orang tamat SMP dan 7 orang tamat SMA. Umur responden rata-rata adalah 43 tahun, dengan lama pengalaman usaha ratarata 12 tahun. Jumlah tanggungan keluarga rata-rata adalah 3 orang.

\section{Indeks Keberlanjutan Dimensi}

Ekonomi. Hasil analisis keberlanjutan dimensi ekonomi (Tabel 1) kesepuluh variabel masuk pada katagori indeks keberlanjutan sedang. Variabel aktif mencari informasi pasar terkait harga, aktif memasarkan hasil panen, mengusahakan agar usaha menguntungkan, aktif memperluas usaha pembesaran, persepsi bahwa usaha lobster menguntungkan, mencari alternatif pendapatan lain, kemudahan akses lembaga keuangan merupakan variabel yang memiliki keterkaitan erat dengan upaya untuk menghasilkan pendapatan yang tinggi dari kegiatan produksi yang dilakukan. Nilai keberlanjutan untuk variabel tersebut belum maksimal, sehingga pembudidaya lobster perlu didorong untuk lebih aktif lagi dalam mencari informasi pasar dan memasarkan produknya, meningkatkan akses ke lembaga keuangan, serta aktif mengupayakan agar usaha lobster lebih berkembang dan menguntungkan di masa mendatang.

Variabel melakukan tindakan pascapanen dan memilih bibit yang bermutu serta ketersediaan sarana dan prasarana produksi yang mendukung juga belum optimal untuk menjamin keberlanjutan usaha pembesaran lobster. Kesadaran pembudidaya untuk melakukan kegiatan penanganan pascapanen agar kondisi hidup lobster tetap terjaga serta pemilihan bibit berkualitas perlu ditingkatkan agar tingkat keberhasilan hidup lobster lebih tinggi. Ketersediaan sarana dan prasarana produksi juga perlu menjadi perhatian pembudidaya untuk lebih ditingkatkan lagi. Ketiga variabel tersebut berhubungan dengan kegiatan produksi, sehingga peningkatan pada ketiganya akan mendukung untuk keberlanjutan usaha selanjutnya.

Tabel 1.

Indeks Keberlanjutan Dimensi Ekonomi

\begin{tabular}{clc}
\hline No & \multicolumn{1}{c}{ Variabel } & Indeks \\
\hline 1 & $\begin{array}{l}\text { Kemudahan akses ke lembaga } \\
\text { keuangan }\end{array}$ & 0.54 \\
2 & $\begin{array}{l}\text { Usaha lobster menguntungkan } \\
3\end{array}$ & 0.54 \\
& $\begin{array}{l}\text { Menggunakan input bibit } \\
\text { bermutu }\end{array}$ & 0.51 \\
4 & Alternatif pendapatan lain & 0.51 \\
5 & Aktif memperluas usaha & 0.58 \\
& pembesaran & 0.54 \\
6 & Mengusahakan agar usaha & \\
& menguntungkan & 0.57 \\
7 & Ketersediaan sarana dan & \\
& prasarana produksi yang & \\
& mendukung & Melakukan tindakan pascapanen \\
9 & Aktif memasarkan hasil produksi & 0.58 \\
10 & Aktif mencari informasi pasar & 0.64 \\
\hline
\end{tabular}

Sumber : Data diolah

Indeks Keberlanjutan Dimensi Sosial. Hasil analisis indeks keberlanjutan pada dimensi sosial (Tabel 2) menunjukkan bahwa variabel kesehatan pelaku usaha berperan penting dalam keberhasilan usaha memiliki nilai indeks keberlanjutan yang masuk pada kategori "tinggi". Dengan kondisi kesehatan yang prima maka pembudidaya bisa menjalankan kegiatan usaha dengan baik. Hasil ini sejalan dengan penelitian Waryanto (2015) Namun demikian keberhasilan dan keberlanjutan usaha pembesaran lobster juga perlu ditopang dengan faktor lain yang melekat pada diri pembudidaya seperti pendidikan, upaya peningkatan skill dan pengetahuan usaha serta aktif dalam kelompok tani. Ketiga variabel tersebut memiliki nilai indeks keberlanjutan "sedang" sehingga pembudidaya masih perlu meningkatkan kapasitas dirinya untuk bisa mendukung keberlanjutan usaha. Shahi et al (2009), Bagheri et al (2008) dan Shardashti et al (2012) menemukan hubungan positif dan signifikan antara pendidikan dengan sistem pertanian berkelanjutan.

Kemudahan pada akses penyuluhan dan kelembagaan petani, merupakan faktor lain di 
luar diri petani yang penting untuk mendukung keberhasilan dan menjamin keberlanjutan suatu usaha tani. Keberadaan penyuluh dan kelembagaan petani akan memberikan solusi bagi permasalahan terutama terkait masalah teknis yang dihadapi oleh petani seperti penentuan ukuran padat tebar bibit yang tepat, penanganan penyakit lobster serta pemberian dosis pakan yang tepat untuk lobster. Variabel kemudahan akses penyuluhan serta kelembagaan petani memiliki nilai indeks keberlanjutan yang masuk pada kategori "sedang". Hal ini berarti kemudahan akses penyuluhan serta peran kelembagaan petani perlu untuk ditingkatkan untuk mendukung keberlanjutan usaha pembesaran lobster. Bagheri et al (2008), Shardashti et al (2012) dan Damghani et al (2005) menemukan hubungan positif peran tenaga penyuluhan terhadap indeks keberlanjutan pertanian

Tabel 2.

Indeks Keberlanjutan Dimensi Sosial

\begin{tabular}{clc}
\hline No & \multicolumn{1}{c}{ Variabel } & Indeks \\
\hline 1 & $\begin{array}{l}\text { Tersedia tenaga kerja untuk } \\
\text { usaha }\end{array}$ & 0.51 \\
2 & $\begin{array}{l}\text { Pendidikan menentukan } \\
\text { keberhasilan usaha }\end{array}$ & 0.47 \\
3 & $\begin{array}{l}\text { Curahan waktu yang optimal } \\
\text { menjadi kunci keberhasilan }\end{array}$ & 0.55 \\
& $\begin{array}{l}\text { usaha } \\
4\end{array}$ & Aktif dalam kelompok tani \\
5 & $\begin{array}{l}\text { Dukungan keluarga sangat } \\
\text { diperlukan }\end{array}$ & 0.47 \\
6 & $\begin{array}{l}\text { Kelembagaan petani sangat } \\
\text { membantu }\end{array}$ & 0.54 \\
7 & $\begin{array}{l}\text { Kemudahan akses penyuluhan } \\
8\end{array}$ & $\begin{array}{l}\text { Meningkatkan skill dan } \\
\text { pengetahuan usaha }\end{array}$ \\
9 & $\begin{array}{l}\text { Kesehatan pelaku usaha } \\
\text { berperan penting }\end{array}$ & 0.49 \\
10 & $\begin{array}{l}\text { Kesejahteraan menjadi tujuan } \\
\text { utama }\end{array}$ & 0.51 \\
\hline
\end{tabular}

Sumber : Data diolah

Keberhasilan dan keberlanjutan dalam usaha pembesaran lobster membutuhkan curahan waktu kerja yang optimal, dukungan dari pihak keluarga serta ketersediaan tenaga kerja yang mencukupi. Variabel curahan waktu kerja yang optimal, dukungan keluarga serta ketersediaan tenaga kerja yang mencukupi juga memiliki nilai indeks keberlanjutan yang masuk pada kategori "sedang", sehingga pembudidaya perlu untuk melakukan manajemen waktu secara lebih baik lagi dan diperlukan kesadaran bagi pihak keluarga untuk lebih meningkatkan dukungan pada usaha pembesaran lobster sehingga berhasil dan bisa berlanjut di masa yang akan datang. Motivasi pembudidaya untuk meningkatkan kesejahteraan perlu didorong sehingga hal ini bisa berimbas pada upaya pengelolaan usaha pembesaran lobster secara lebih baik. Motivasi pada kesejahteraan akan mendukung keberhasilan dan orientasi keberlanjutan usaha pembesaran lobster.

\section{Indeks Keberlanjutan Dimensi}

Lingkungan. Hasil analisis keberlanjutan untuk dimensi lingkungan (Tabel 3), hanya terdapat dua variabel yang masuk pada kategori indeks keberlanjutan "tinggi" yaitu variabel melakukan perawatan sarana dan prasarana produksi dengan baik (0.73) serta melakukan penilaian kesesuaian lokasi untuk usaha pembesaran (0.68). Kesadaran pembudidaya dalam melakukan perawatan sarana produksi dan pemilihan lokasi usaha yang tepat mendukung keberhasilan dan keberlanjutan usaha pembesaran lobster. Variabel lain seperti mencegah dan mengatasi penyakit, membersihkan sisa pakan, menggunakan dosis pakan yang sesuai, penyesuaian ukuran cacahan pakan dengan ukuran lobster, mencari informasi teknologi pakan, menjaga kebersiha karamba, menggunakan konstruksi karamba yang sesuai serta memperhatikan sirkulasi air semuanya memiliki nilai indeks keberlanjutan yang masuk pada kategori "sedang".

Tabel 3.

Indeks Keberlanjutan Dimensi Lingkungan

\begin{tabular}{clc}
\hline No & \multicolumn{1}{c}{ Variabel } & Indeks \\
\hline 1 & $\begin{array}{l}\text { Melakukan penilaian kesesuaian } \\
\text { lokasi karamba }\end{array}$ & 0.68 \\
2 & $\begin{array}{l}\text { Memperhatikan sirkulasi air } \\
\text { Menggunakan model dan }\end{array}$ & 0.58 \\
3 & 0.60 \\
& $\begin{array}{l}\text { konstruksi karamba yang sesuai } \\
4\end{array}$ & Menjaga kebersihan karamba \\
5 & $\begin{array}{l}\text { Mencari informasi teknologi } \\
\text { pemberian pakan, nutrisi dan }\end{array}$ & 0.61 \\
& $\begin{array}{l}\text { penyakit } \\
6\end{array}$ & $\begin{array}{l}\text { Melakukan perawatan sarana dan } \\
\text { prasarana produksi dengan baik }\end{array}$ \\
7 & $\begin{array}{l}\text { Menyesuaikan ukuran cacahan } \\
\text { pakan dengan ukuran lobster }\end{array}$ & 0.73 \\
8 & $\begin{array}{l}\text { Menggunakan dosis pakan sesuai } \\
\text { kebutuhan lobster }\end{array}$ & 0.55 \\
9 & $\begin{array}{l}\text { Membersihkan sisa pakan lobster } \\
10\end{array}$ & $\begin{array}{l}\text { Mencegah dan mengatasi } \\
\text { timbulnya penyakit pada lobster }\end{array}$ \\
\hline
\end{tabular}

Sumber : Data diolah 
Keseluruhan variabel tersebut merupakan faktor yang memiliki keterkaitan erat dengan upaya menyesuaian serta menjaga kondisi lingkungan perairan di sekitar karamba agar tetap mendukung untuk keberhasilan dan keberlanjutan usaha pembesaran lobster. Pembudidaya perlu didorong untuk memperhatikan faktor-faktor yang berkaitan dengan keseimbangan ekosistem lingkungan perairan sekitar karamba sehingga daya dukung lingkungan tetap terjaga untuk menjamin keberlanjutan usaha budidaya pembesaran lobster.

\section{Indeks Keberlanjutan Dimensi} Ekonomi, Sosial, Lingkungan dan Indeks Gabungan. Nilai indeks keberlanjutan untuk dimensi ekonomi, sosial dan lingkungan masing-masing masuk pada katagori keberlanjutan "sedang" dengan nilai rata-rata adalah 0.58; 0.56 dan 0.54 (Tabel 4).

Tabel 4.

Analisis Keberlanjutan Usaha Pembesaran Lobster di Pulau Lombok

\begin{tabular}{lllll}
\hline \multicolumn{1}{c}{ Dimensi } & \multicolumn{3}{c}{ Nilai Indeks } & Katagori \\
& \multicolumn{3}{c}{ Keberlanjutan } & \\
\cline { 2 - 4 } & $\begin{array}{c}\text { Rata- } \\
\text { rata }\end{array}$ & Min & Max & \\
\hline Ekonomi & 0.58 & 0.36 & 0.91 & Sedang \\
Sosial & 0.56 & 0.23 & 0.83 & Sedang \\
Lingkungan & 0.54 & 0.23 & 0.81 & Sedang \\
Gabungan & 0.56 & 0.27 & 0.75 & Sedang \\
\hline Sunber : Datan & diah & & & \\
\hline
\end{tabular}

Sumber : Data diolah

Interaksi antara ketiga dimensi yang ditunjukkan oleh indeks gabungan memiliki nilai yang berkisar antara 0.27 sampai 0.75 , dengan rata-rata 0.56 masuk pada katagori sedang. Hal ini berarti bahwa usaha pembesaran lobster masih belum bisa menjamin keberlanjutan dalam jangka panjang pada ketiga dimensi tersebut. Secara ekonomi, usaha pembesaran lobster masih belum optimal dalam mendukung kehidupan pembudidaya. Sehingga masih dimungkinkan adanya kerugian yang bisa diterima dari usahanya. Secara sosial, masih belum bisa optimal menjamin terwujudnya kesejahteraan sosial pembudidaya. Kemudahan akses penyuluhan, peran kelembagaan petani, dukungan keluarga, manajemen waktu yang optimal, serta pengembangan kapasitas diri pembudidaya masih perlu ditingkatkan untuk mendukung keberhasilan dan keberlanjutan usaha pembesaran lobster. Pada dimensi lingkungan, usaha pembesaran lobster juga masih belum bisa menjamin aman terhadap ekosistem lingkungan perairan. Penggunaan dosis pakan yang tidak tepat, penebaran benih yang tidak sesuai serta tidak adanya penanganan penyakit pada lobster bisa menjadi kendala untuk keberlanjutan usaha. Karenanya diperlukan sentuhan teknologi untuk menangani hal tersebut sehingga bisa mendukung pengembangan dan keberlanjutan usaha pembesaran lobster di masa yang akan datang.

\section{KESIMPULAN}

Berdasarkan hasil perhitungan indeks keberlanjutan dapat disimpulkan bahwa indeks keberlanjutan masuk dalam kategori sedang, baik untuk dimensi ekonomi, sosial maupun lingkungan dengan nilai indeks masingmasing sebesar $0.58 ; 0.56$ dan 0.54 . Interaksi gabungan antara ketiga dimensi tersebut masuk dalam kategori sedang dengan nilai sebesal 0.56. Dalam penelitian ini aspek keberlanjutan diukur hanya berdasarkan persepsi petani, sehingga diperlukan penelitian lanjutan yang melibatkan data yang memasukkan parameter fisik dan lingkungan perairan tempat dilakukannya usaha pembesaran lobster.

\section{UCAPAN TERIMAKASIH}

Penulis mengucapkan terimakasih kepada Samsul Bahri yang telah memberikan arahan dan bantuan dalam pengambilan data. Serta kepada responden yang telah bersedia meluangkan waktu untuk wawancara.

\section{DAFTAR PUSTAKA}

Bagheri A., Shabanali Fami, Rezvanfar, Asadi Yazdani. 2008. Perceptions of Paddy Farmers towards Sustainable Agricultural Technologies: Case of Haraz Catchments Area in Mazandaran province of Iran American Journal of Applied Sciences 5 (10): 1384-1391

Bhossaq MR, Afzalinia F, Moradi H. 2012. Measuring indicators and determining factors affecting sustainable agricultural development in rural areas - a case study of Ravansar, Iran. Int'l Journal of Agri Science Vol 2(6): 550-557. June 2012.

Ceyhan V. 2010. Assesing the Agricultural Sustainability of Conventional Farming Systems in Samsun Province of Turkey. African Journal of Agricultural 
Research, 5(13): 1572-1583

Damghani M.A, Koocheki A, Rezvani Moghaddam P.R., Mahallati M.N., 2005. Ecological Sustainability of a Wheat-cotton Agroecosystem in Khorassan. Journal of Iran Agricultural Researches. 3(1): 129-142.(Abstract) Gunduz, O, Ceyhan V, Erol E, Ozkaraman F. 2011. An Evaluation of Farm Level Sustainability of Apricot Farm in Malatya Province of Turkey. J. of Food, Agriculture \& Environment. 9 (1) : 700-705

Kementerian PPN/Bappenas. 2014. Kajian Strategi Pengelolaan Perikanan Berkelanjutan. Jakarta.

Shahi H, Iravani H, Kalantari K.H. 2009. Evaluation Status of Maintenance Levels Sustainability Agricultural
System's Wheat Farmers Member of Production Cooperation Corporation Fars Province. Journal of Economics Researches and Agricultural Development. 40(2): 135-143.

Sardashti Z.H., Al-Ahmadi M.J, Behdani M.A., Damghani M.A. Evaluation of Social-Economic Sustainability Indicators Among All Constitutive Indicators in Some Parts of Southern Khorasan Province International Research Journal of Applied and Basic Sciences. Vol., 3 (7), 1520-1526

Waryanto B. 2015. Analisis Keberlanjutan Usaha Tani Bawang Merah di Kabupaten Nganjuk Jawa Timur [Disertasi]. Bogor (ID). Institut Pertanian Bogor. 